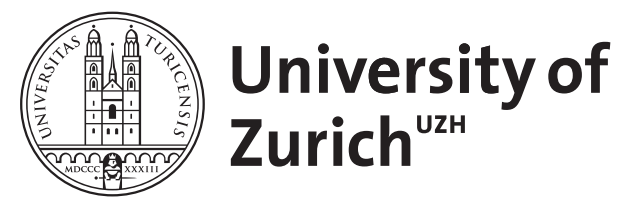

\title{
The Duty of the patient to cooperate
}

Löschke, Jörg

\begin{abstract}
In discussing the normative implications of the doctor-patient relationship, medical ethics has mostly focused on the duties of doctors to their patients. This focus neglects an important normative dimension of the doctorpatient- relationship, namely the duties of patients to doctors. Only few authors have discussed the content and ground of the moral duties of patients, and each of these accounts are wanting in some way. This paper discusses patients' duties and argues that patients have a relationshipdependent obligation to cooperate with the doctor, because doctors have a morally justified interest in fulfilling their moral role obligations as doctors, and by not cooperating, patients make it more difficult for doctors to fulfill their moral obligations. In some cases, failing to cooperate might even create an avoidable moral dilemma for the doctor.
\end{abstract}

DOI: https://doi.org/10.1515/jwiet-2017-0103

Posted at the Zurich Open Repository and Archive, University of Zurich ZORA URL: https://doi.org/10.5167/uzh-169685

Book Section

Published Version

Originally published at:

Löschke, Jörg (2017). The Duty of the patient to cooperate. In: Sturma, Dieter; Heinrichs, Bert; Honnefelder, Ludger. Jahrbuch für Wissenschaft und Ethik. Berlin/Boston: De Gruyter, 7-26.

DOI: https://doi.org/10.1515/jwiet-2017-0103 


\title{
The Duty of the Patient to Cooperate
}

\begin{abstract}
In discussing the normative implications of the doctor-patient relationship, medical ethics has mostly focused on the duties of doctors to their patients. This focus neglects an important normative dimension of the doctorpatient-relationship, namely the duties of patients to doctors. Only few authors have discussed the content and ground of the moral duties of patients, and each of these accounts are wanting in some way. This paper discusses patients' duties and argues that patients have a relationship-dependent obligation to cooperate with the doctor, because doctors have a morally justified interest in fulfilling their moral role obligations as doctors, and by not cooperating, patients make it more difficult for doctors to fulfill their moral obligations. In some cases, failing to cooperate might even create an avoidable moral dilemma for the doctor.
\end{abstract}

Keywords: Patients’ Duties, Doctors' Duties, Role Obligations, Doctor-Patient Relationship, Principlism

\section{Introduction}

Medical ethics has a clear focus. For the most part it discusses the rights of patients and the accompanying duties of doctors and other health care workers. This focus seems justified - after all, patients are especially vulnerable, both because of their predicament and their dependency, and it is important to protect that vulnerability. At the same time, the focus on the rights of patients and the duties of doctors has led to neglect of the possible duties of patients to their doctors and other health care workers. While the possible duties of patients have not been entirely ignored in the literature, ${ }^{1}$ the topic certainly remains underexplored. ${ }^{2}$

This is unsatisfactory. An important task of medical ethics is to analyze the normative complexity of the various relationships within a specific health care system - relationships such as the relationship between doctors and patients,

1 For an overview of the few texts that discuss the duties of patients, see Kangasniemi et al. 2012.

2 Cf. Meyer 1992. Not much has changed since the publication of that essay. 
nurses and patients, patients and patients, or even patients and other stakeholders within the health care system such as tax payers. These different kinds of relationships all bear normative significance, and to come to a justified judgment concerning the duties that arise within these relationships one must analyze the relevant normative considerations that apply to them. While the rights of patients and the accompanying duties of doctors are very important considerations within the normative web of a healthcare system, they are certainly not the only considerations that count. To fully grasp the normativity of health care, more work needs to be done. An analysis of patients' duties is part of that work, and is relevant for various debates in medical ethics.

For example, some authors criticize what they see as a one-sided focus on the autonomy of patients within medical ethics. ${ }^{3}$ Understanding patients as bearers not only of moral rights but also of moral duties also emphasizes their autonomy, albeit a neglected aspect of it; ${ }^{4}$ at the same time, the grounds of patients' duties might very well show that it is misleading to focus merely on patients' autonomy when analyzing the normative implications of the doctorpatient relationship. As I will argue, duties of patients are derivative of the duties of doctors, but the relevant duties of doctors are not exhausted by their duty to respect the autonomy of their patients. If this is correct, it follows that the autonomy of patients is not the only relevant normative consideration that applies to the doctor-patient relationship.

The question of possible moral duties of patients is relevant for other debates too. How should we understand the doctor-patient relationship? As a hierarchical relationship, as a partnership with a more egalitarian structure, or as a relationship between service-provider and customer? Is it appropriate to commercialize the healthcare system? How much self-responsibility can we demand from members of a healthcare system? The answers to these questions depend (among other things) on whether patients have duties to their doctors, and if they do, on what grounds.

Hence, exploring patients' duties is a worthwhile endeavor. In what follows, I will argue that patients do have a duty to cooperate with their doctors, and I will offer a novel argument for this claim. This is a fairly modest task. I do not attempt to offer a full account of patients' duties, since such an account would also have to discuss the duties that patients have to all stakeholders within a specific healthcare system, and that task is too great for a single paper. The duty that I am interested in is a duty that stems from the doctor-patient

3 See, for example, Foster 2009; Schneider 1998; O’Neill 2002.

4 I will discuss this aspect in more detail below. 
relationship, and this leaves open the possibility that patients also have duties to other stakeholders.

I will proceed as follows. First, I analyze the doctor-patient relationship to get a better understanding of its distinct normativity. I will then discuss some prominent accounts of patients' duties and argue that each of them fails to capture important aspects. In a third step, I offer a novel account, according to which patients have a duty to cooperate because doctors have a justified interest in fulfilling their moral role obligations. I close with some concluding remarks.

\section{The normative complexity of the doctor-patient relationship}

I understand the duties of patients as duties that stem from the doctor-patient relationship. ${ }^{5}$ This relationship is normatively complex, for several reasons. Most importantly, doctors are asked to make complex decisions when interacting with their patients, as they have to take several aspects into account that ought to govern their actions. The influential principlist account of Beauchamp and Childress ${ }^{6}$ expresses this complexity: according to this account, four moral principles are relevant for doctors when interacting with their patients, namely respect for the patient's autonomy, beneficence, non-maleficence, and justice. These principles cannot be reduced to one overarching meta-principle of biomedical ethics. Rather, they can conflict, and such conflicts might even amount to moral dilemmas, which is one reason why the doctor-patient relationship is normatively complex. Other factors also add to this normative complexity: the patient's age, the seriousness of his situation, or decisions regarding third parties all influence the doctor's decisions regarding what action to take, without a

5 Very generally speaking, a moral duty is a "sufficient moral reason to do or refrain from doing something” (Seglow 2013, 6). In other words, whenever an agent has a moral duty, this fact by itself can explain why she ought to do something. But duties can be more or less stringent. William David Ross 1930 distinguishes prima facie duties from actual duties: a prima facie duties holds as long as it is not outweighed by other relevant considerations. By contrast, an actual duty is an all-things-considered judgment about what an agent ought to do in a given situation. Hence, prima facie duties contribute to the actual duty of an agent, but these kinds of duty need not be identical. The duty of a patient to cooperate is to be understood as a prima facie duty: it can be outweighed by other relevant considerations.

6 Cf. Beauchamp, Childress 2012. 
clear criterion for how to weigh such factors. To say that the doctor-patient relationship is normatively complex is to say that doctors face complex decisions.

But this is not the only dimension of complexity within the doctor-patient relationship. Personal relationships as such have an inherent normativity insofar as they imply rights and duties of all parties involved - the only exception being the relationship between parents and their very young children. Another dimension of complexity thus arises because all of the participants within relationships owe duties to each other.

One might think that talking of patients' duties is out of place, for the reason already mentioned: patients are the vulnerable part of the doctor-patient relationship, and it seems more important to protect that vulnerability than to talk about their duties. However, while it is true that patients are the vulnerable part of the relationship, it does not follow that they bear no duties. In fact, there seem to be good reasons to think of patients as bearers of obligations, the most important being the patient's autonomy. ${ }^{7}$ One of the moral principles that applies to the doctor is the duty to respect the patient's autonomy, and this is important because it avoids hierarchical conceptions of the doctor-patient relationship according to which the patient is a helpless person who needs others to look after her good. However, the autonomy of an agent not only grounds rights of that agent, but also duties. Generally speaking, the autonomy of an agent is both a necessary and a sufficient condition for her being the bearer of moral obligations, and to understand the patient as an autonomous part of the doctorpatient relationship therefore implies understanding her as a responsible participant of that relationship too - as a person who can be held accountable for her actions. If one thinks that respect for the patient's autonomy is an important principle in medical ethics, one that grounds patients' rights and doctors' duties, one should also take seriously the idea that patients are bearers of moral duties.

To sum up, two considerations support the idea that patients have duties: first, the fact that the doctor-patient relationship has normative significance, and second, the fact that the autonomy of patients must be taken seriously. However, while these considerations suggest that patients have duties, they do not elucidate the grounds and content of those duties. Relationships have a distinct normativity, since their participants owe each other so-called associative duties, not merely in virtue of their humanity, but in virtue of their relation-

7 Meyer 1992. 
ship. ${ }^{8}$ But even if such duties exist in virtue of the relationship, their exact grounds and content can differ, depending on the kind of relationship that grounds them. One must analyze the normativity of a given kind of relationship in order to determine what the participants owe to each other, and thus, one cannot fully understand the duties of patients without analyzing the specific characteristics of the doctor-patient relationship.

\section{The doctor-patient relationship}

Most authors assume that associative duties stem from the intrinsic value of the relationship that gives rise to them, where the intrinsic value of a relationship consists in that relationship contributing directly to the flourishing or the wellbeing of the participants. ${ }^{9}$ In other words, the participants take part in such relationships not because doing so helps them to achieve some goal that is exterior to the relationship, but rather because participating in these relationships is considered worthwhile in itself: a person who engages in a friendship not for the relationship's sake, but to achieve fame or wealth, is no real friend. However, the doctor-patient relationship is not intrinsically valuable in the way that friendships or romantic partnerships are. Patients do not enter a doctor-patient relationship because they regard it as worthwhile in itself - rather, they do so because they have a medical problem and need help.

Given that it is not intrinsically valuable in the same way as personal relationships such as friendships or romantic partnerships, one might think that the duties arising from a doctor-patient relationship can be reduced to duties stemming from contractual relationships. But this seems implausible. Contractual relationships are valuable, but only instrumentally, and this is why such a reduction fails to capture the normativity of the doctor-patient relationship. While it is true that a doctor-patient relationship is instrumentally valuable (especially for the patient), it differs in an important respect from other contractual relationships, as it can shape the identities of the participants profoundly. People are typically quite indifferent to their contractual relationships, but their status as a doctor or as a patient can be an important part of their self-understanding.

8 For different versions of this view, see, among others, Scheffler 2002; Kolodny 2003; Seglow 2013.

9 This does not contradict the claim that the exact grounds of relationship-dependent duties can differ, depending on the relationship in question - after all, the reason why certain relationships contribute to the well-being of their participants can differ. 
The doctor-patient relationship is a relationship that is not intrinsically valuable, but that can nevertheless shape the identities of the parties involved. This seems to be best captured by characterizing the doctor-patient-relationship as one of mutually dependent social roles. ${ }^{10}$ Social roles are often (at least partly) constitutive of the role-bearer's identity. Therefore, understanding the doctor-patient-relationship in terms of social roles explains why one's own standing in such a relationship, either as a doctor or as a patient, can (partly) shape one's self-understanding. At the same time, people do not necessarily occupy social roles because they consider this worthwhile in itself, and this explains why the doctor-patient relationship is not intrinsically valuable.

It is important to see that the roles of doctor and patient are not freestanding but mutually dependent: the one cannot exist without the other - one cannot occupy the role of a doctor without somebody occupying the role of a patient, and at the same time, a patient is not merely a sick person, but a sick person seeking help from a doctor. Thus, the roles of doctor and patient mutually depend on each other - I will return to this point.

Understanding the doctor-patient relationship in terms of social roles explains the relationship's inherent normativity, because social roles are normative concepts: they imply role obligations. ${ }^{11}$ These obligations are not static; rather, role obligations depend on socially shared understandings of what it means to be a bearer of the role in question. These shared understandings can change over time, and they can also change within a specific social context. In other words, roles are interpretative concepts: ${ }^{12}$ they must be interpreted, and a change in the shared understanding of a role can be described as a change in the paradigmatic interpretation of this role. The doctor-patient-relationship exemplifies such a change. The roles of doctor and patient used to be interpret-

10 For an account of the doctor-patient relationship in terms of social roles, see also Parsons 1951; 1975. Parsons thinks that patients have a role-related obligation to cooperate with their doctors. However, his view differs from the one developed in this paper in an important regard: Parsons understands the obligations of the "sick role" as obligations whose function it is to deal with deviant behavior, thereby stabilizing a social system. By contrast, the focus of this paper is the moral grounds of the patient's obligation to cooperate with the doctor.

11 Hardimon 1994. It is important to stress at this point that role-obligations are not necessarily moral obligations. It is possible to analyze the role obligations of women within patriarchic societies, without thereby showing - or even claiming - that such obligations are morally justified. However, some role obligations are moral obligations - one might even understand certain social roles as means to discharge moral requirements. And at least some of the role obligations of physicians belong to this category. I will return to this point below.

12 Cf. Dworkin 1986. 
ed in terms of the authority of the doctor and the obedience of the patient, but this has gradually changed to an understanding of the doctor-patient relationship in terms of a partnership. ${ }^{13}$

To conclude, the relationship between patient and doctor must be understood as a relationship of mutually dependent social roles. This understanding explains not only the duties of doctors, but also the duties of patients to their doctors, in particular a duty to cooperate - or so I will argue.

Before I will develop this thought, let me first discuss some accounts of patients' duties that can be found in the literature. They each identify a duty to cooperate with the doctor, but they all seem insufficient in one way or another.

\section{Patients' duties: insufficient accounts}

One might think that the duty to cooperate with the doctor is a duty that the patient owes to herself, rather than to the doctor or to some other party - after all, it is her health or well-being that is at stake. ${ }^{14}$ But this does not seem convincing. First, it is hard to see how others can hold a person accountable for violating a self-regarding duty. But when a patient fails to cooperate with her doctor, there seem to be grounds for holding her accountable, even if it might not be immediately clear who has the standing to hold her accountable and on what grounds. Second, if the duty to cooperate were a self-directed duty, the patient would also have a self-regarding duty to seek help from a doctor in the first place. If patients owe it to themselves to cooperate with the doctor because their health is at stake, then surely they also owe it to themselves to seek help from a doctor. But there seems to be a normatively relevant difference between failing to seek help from a doctor and failing to cooperate with the doctor, once one has sought help from her. ${ }^{15}$

Michael J. Meyer argues that doctors and patients share a "commitment to the practice of bilateral decision-making"16. According to Meyer, this practice constitutes an ethically relevant relationship, and the duties of patients are

13 Meyer 1992, 545.

14 I am not aware of any author who actually holds this position; I only mention it to set it aside.

15 I thank an anonymous referee for making me aware of the need to explain why the patient's duty to cooperate should not be understood as a self-regarding duty.

16 Meyer 1992, 545. 
"duties born of that partnership"17. These duties consist in various kinds of cooperation - being honest, collecting information on treatments and side-effects, and taking measures to avoid the transmission of an infectious disease. By fulfilling these duties, the patient proves to be a cooperating partner in the relationship.

Understanding the relationship between patient and doctor as a relationship of bilateral decision-making and as the source of (at least some of) the patient' duties is quite plausible. However, this claim does not elucidate the exact grounds of those duties: different kinds of relationships (and different kinds of partnerships) ground duties in quite different ways. The justification of duties within intrinsically valuable relationships (or partnerships) differs from the justification of such duties within merely instrumentally valuable relationships. And this marks an important difference: for example, duties of friendship hold (at least to a degree) even if the other party of the relationship has failed to fulfill her obligations, whereas duties of business partnerships can cease as soon as the other party fails to fulfill her obligations. Hence, an account that grounds the duties of patients within the doctor-patient relationship must explain in what exact way this relationship grounds duties, and this is why Meyer's account is insufficient.

Heather Draper and Tom Sorell identify several duties that fall to patients, including a duty to cooperate. They ground this duty in the combination of two considerations: a general duty to follow advice one has asked for (as long as the patient genuinely agrees with it), and considerations of fairness. However, neither of these considerations seems to ground patients' duties to cooperate.

According to Draper and Sorell, the first consideration arises from a specific sort of moral practice, namely the "rules of situations in which people seek and are given medical advice"18. The authors see a duty to cooperate as stemming from a general rule in counseling relationships: when an agent asks for advice, he ought to follow it as long as he has good reason to believe that the advicegiver puts his interests first. And the authors understand this as a moral requirement.

However, it is not clear that such a general moral requirement exists. If it were, the advice-seeker would be answerable to the advice-giver when he fails to follow the advice - in other words, he would owe the advice-giver some explanation or apology. But there are many cases in which a person who fails to follow advice is not answerable to his advice-giver, even if he acts imprudently.

17 Meyer 1992, 547.

18 Draper, Sorell 2002, 346. 
For example, if I meet a stranger in a bar and learn that he is a financial expert, I might ask him for advice on how to invest my money. ${ }^{19}$ But it certainly does not follow that I have a moral obligation to follow his advice, or that I ought to apologize to him if I decide not to follow his advice. Hence, even if a patient has a moral obligation to follow advice he has asked for, this obligation does not stem from a general moral rule according to which persons who ask for advice have an obligation to follow it.

The second consideration claims that the doctor-patient relationship can be unjust for the doctor, since she cannot unilaterally end the relationship, even if the patient fails to follow her advice. The patient, on the other hand, can unilaterally end the relationship. This leads to the danger of the doctor becoming a "captive helper"20. Draper and Sorell argue that this constitutes a specific form of unfairness. Accordingly, the patient's duty to cooperate exists because by cooperating, the patient reduces this specific kind of unfairness.

An obvious objection to this argument, as Draper and Sorell themselves recognize, is that "doctors enter the profession knowing that there will be difficult patients, including patients who repeatedly ignore important medical advice"21. Since doctors are aware of this possibility when they choose their profession, it does not seem unfair that doctors cannot end the relationship in the same way as patients.

Against this possible objection, Draper and Sorell argue that "the fact that a kind of behaviour is to be expected is not justification of the behaviour"22. They use the division of labor between men and women as an example to support this claim: women used to have to expect an unfair division of labor after marriage and knew this before entering a marriage. However, this did not justify this unjust practice.

While it is true that the fact that women had to expect an unfair division of labor does not justify this arrangement, it is less clear that the example rebuts the objection against the "captive helper" argument. As was argued before, roles are interpretative concepts, and the roles of husband and wife used to be interpreted in a way that assigned women a lower status. Hence, there was a moral requirement to re-interpret these roles in a more egalitarian way. But this does not apply to the doctor-patient relationship. Even if one considers it unfair that doctors cannot leave the relationship as freely as patients can, this does not

\footnotetext{
19 See Darwall 2013.

20 Draper, Sorell 2002, 346.

21 Ibid., 348.

22 Ibid.
} 
imply a lower status on the part of doctors. Furthermore, it is not clear how to re-interpret the roles of patient and doctor accordingly. Either it would require limiting the possibility for patients to leave the relationship, which threatens their autonomy, or it would imply enabling doctors to end the relationship unilaterally, which increases patients' vulnerability. Hence, the "captive helper" argument seems just as insufficient to ground patients' duties as the argument from the moral duty to follow advice one has asked for.

Stephen Buetow understands the duty to cooperate with the doctor as a dischargeable moral debt that the patient owes the state: patients benefit from healthcare services provided by the state, and this grounds an obligation to help keep health costs to a minimum. Cooperation with the doctor is an indispensable means to this end. ${ }^{23}$

As plausible as such considerations of fairness are, they fail to give a fully satisfactory account of patients' duties. The argument assumes that the patient's duty to cooperate is not a duty that is directed to the doctor, but rather to the state, even if the doctor figures in the content of that duty. The direction of a duty determines who can demand fulfillment of that duty, namely the party towards whom the duty is directed. On Buetow's account, patients' duties are owed to the state; hence, according to this account, the state or every member of the healthcare system can demand compliance with the doctor's advice from the patient. In other words, not just the doctor, but any stranger has the authority to demand cooperation, as long as he is a representative of the shared healthcare system. But this seems wrong. Such a general standing to demand cooperation from patients seems to unduly interfere with the patient's autonomy: in a way, her behavior is none of a stranger's business. Doctors might not be in the position to issue orders to the patient, but they do have a special normative authority to ask the patient to cooperate. Their standing to do so exceeds the standing of strangers - this simply follows from the assumption that patients' duties stem from the doctor-patient relationship. But Buetow's account cannot accommodate such special standing to demand cooperation. This is not to say that the normative web of a health care system does not also include duties of the patient to the state. It just means that this duty does not exhaust the patient's duty to cooperate with the doctor.

Martyn Evans identifies ten patients' duties in total, three of which are duties of cooperation: the duty of truthfulness, the duty of compliance, and the duty of recovery or maintenance. According to Evans, these duties are grounded

23 Buetow 2005, 305. 
in the "good of all other patients" ${ }^{24}$. His argument runs as follows: medical resources are scarce; hence, a patient has an obligation to other patients to keep the resources used for his recovery to a minimum, and this amounts to a duty to cooperate with the doctor, as uncooperative patients waste resources that other patients need for their recovery. This argument seems quite similar to Buetow's account, but the crucial difference concerns the directedness of the patients' duties: they are owed to other patients, not to the state (or representatives or the shared health system). This difference in the directedness of patients' duties does not solve the problem that arises for Buetow's account, but rather makes it worse. According to Evans' account, a doctor has no moral standing whatsoever to demand cooperation from the patient: he is a representative of the shared healthcare system, but he is not a patient. However, every other patient within that health care system has a justified claim on the patient's behavior. Hence, Evans's account also fails to show why a doctor has a special standing to demand cooperation from the patient, and this means that it cannot elucidate an important part of the normative web of healthcare..$^{25}$

\section{Patients' duties}

A more satisfying account of the duty of patients to cooperate can be developed by taking seriously the idea that the doctor-patient relationship is a relationship of mutually dependent social roles. As a normative concept, the role of a patient implies obligations in a way that I will explain shortly. But first, it is necessary to discuss a possible objection against understanding patients' duties as role obligations.

Persons do not (usually) choose to be sick; hence, they do not voluntarily occupy the role of patient. Role obligations, the objection goes, might be justified when the role-bearer voluntarily takes over a role, as she then consents to the obligations. But role obligations that stem from roles that the role-bearer has not consented to can easily become oppressive. For example, in sexist societies,

24 Evans 2007, 691.

25 This is not to say that patients have no duty whatsoever to other members of their shared healthcare system. They might very well have such duties; and one of the reasons why patients have duties to doctors might implicitly assume that members of a certain healthcare system have duties to act so as to keep health care costs to a minimum. However, even if such duties exist, they do not fully account for the duties of patients to their doctors, as they do not appropriately focus on the doctor-patient relationship and its normative structure. 
the role obligations that come with the role of a housewife can greatly violate the role-bearer's right to an autonomous way of life. And insofar as a person does not choose to be sick, she does not consent to being a bearer of role obligations. Hence, one might think that any obligations that come with the role of a patient are also unjustified.

This possible objection can be rebutted. From the fact that a person did not voluntarily take over a specific role, it does not follow that no normative considerations apply to her in virtue of that role. As Michael Hardimon has argued, role obligations can also hold if the role-bearer can accept his non-voluntarily acquired role upon rational reflection. ${ }^{26}$ In other words, he must be able to judge the role as good, meaningful, or otherwise acceptable. And the role of a patient seems to meet this requirement. Of course, people do not typically judge their disease as good or meaningful. But the role of the patient is not equivalent to the role of being sick, since a patient is a sick person seeking help. And as a sick person, it is good for her that social practices exist which enable that person to seek help from qualified helpers. If the principle of reflective acceptability holds, the role of a patient can imply normative requirements that hold even if the role-bearer does not occupy the role voluntarily.

However, these considerations only support the idea that patients have role obligations, which is just to say that patients are subject to social expectations. They do not tell us the exact content of such obligations - and they do not show that they are moral obligations. Not all role obligations are moral obligations. ${ }^{27}$ For example, a football coach has role obligations such as not making a substitution in the last minute of the game if his team is trailing by one goal and needs every second to score. But this is not a moral obligation. The question, then, is whether the role obligations of patients are in fact moral obligations, or whether they are just non-moral social expectations.

At this point, it is important to remember that the roles of patient and doctor are mutually dependent. Nevertheless, the doctor's role has conceptual priority - this follows from the fact that a patient is a sick person seeking help from a doctor. The role of the doctor is necessary to turn a person with a disease into a patient: the role of a patient can only exist if the role of a doctor exists. However, the role of a doctor not only has conceptual priority, but also a specific kind of normative priority, and this explains why the role obligations of patients are moral obligations.

26 See Hardimon 1994.

27 Cf. Sciaraffa 2011. 
To see this, consider first the role obligations of doctors. Some role obligations of doctors are not genuinely moral in character - a doctor might be expected to attend board meetings, but this is a non-moral obligation. But other role obligations of doctors are clearly moral in character. For example, the aforementioned principles of biomedical ethics identified by Beauchamp and Childress can be understood along these lines. Respect for the patient's autonomy, beneficence, non-maleficence, and justice are moral principles that define doctors' duties to their patients, and as such, they define the obligations that doctors have to their patients as doctors. However, these principles not only explain the duties of doctors to patients, but also the duties of patients to doctors - this is what the normative priority of the doctor's role consists in. Let me explain.

If an agent has a moral role obligation to do something, she also has a morally justified interest in fulfilling her obligation. ${ }^{28}$ For example, a mother has a moral duty to care for her child, and thus she has a justified interest in caring for her child. And this extends to other forms of obligations: I have a moral obligation not to deliberately kill another person, and hence, I have a justified interest in not having to deliberately kill another person. Of course, there might be agents who have a moral obligation to do something, but who do not want to do what they are obligated to do; agents who, in other words, show no interest in fulfilling their obligations. But such cases do not speak against the general claim that, if a person has a moral obligation to do something, and if she wants to fulfill her obligation, she has a justified interest in doing so.

A morally justified interest of a person to fulfill her obligations grounds moral duties on behalf of other persons. ${ }^{29}$ Some of these are positive duties, that

28 In what follows, I draw from ideas that have been formulated by Leif Wenar 2013.

29 Here I assume an interest theory of rights. For such a theory, see, among others, Raz 1989 and Brighouse, Swift 2014. However, I do not argue for a general correlativity of rights and duties. Discussing such a correlativity thesis is outside the scope of this article. Clearly, not every duty implies a right on behalf of others (Raz 1989, 7). But if we follow John Stuart Mill and think that "[t]o have a right [...] is [...] to have something which society ought to defend me in the possession of" (Mill 1969, 250), then rights are defined at least partly in terms of the duties of others. I have no space to discuss these conceptual questions here, and I do not make the strong claim that rights and duties necessarily imply each other. Rather, I make the assumption that persons who have a moral duty have a right to act accordingly, and I take this claim to be fairly uncontroversial. It must be noted that this is not equivalent to a right to fulfill one's obligations; morality might include competitive elements, where my fulfilling a duty (say, to secure a good for my child) prevents you from fulfilling your obligation (say, securing the same good for your child). I thank an anonymous referee for making me aware of the need to discuss the correlativity thesis. 
is, duties to help that person in fulfilling her obligations. The public support of parents can be understood along these lines. Such positive duties might be controversial, but what seems uncontroversial is that the morally justified interest of a person in fulfilling her obligations grounds the negative duties of other agents not to deliberately interfere with her in ways that hinder her in fulfilling her obligations. If you know that your colleague needs to pick up his children from school, it would be wrong to deliberately set a meeting at that time if alternatives are available, given that in doing so, you hinder your colleague from fulfilling his obligations as a father. And, of course, this extends to other kinds of moral obligations. For example, agents have a moral obligation not to create avoidable moral dilemmas for others, because moral dilemmas just consist in agents not being able to fulfill all of their obligations.

Taken together, these considerations explain both the ground and the content of the duties of patients to doctors. Doctors have duties to their patients that exist in virtue of their relationship, such as the aforementioned duties of beneficence, non-maleficence, justice, and respect. The patient figures not only in the content of these duties - the doctor has a duty to act beneficially on behalf of her patient - but also in the direction of the doctor's duties, as the doctor owes fulfillment of his duties to the patient, rather than to some third party. These points are not equivalent: if I promise my friend to take his daughter to the zoo, then his daughter figures in the content of my duty (I ought to take her to the zoo), but I owe fulfillment of the duty to my friend, since he is the one to whom I gave the promise. Hence, if I fail to take my friend's daughter to the zoo, I am not necessarily wronging her - I am wronging my friend. But in the case of doctors and patients, the patient not only appears in the content of the doctor's duties, he is also the party towards whom the duties are directed.

Since the patient figures in the content of the doctor's duties as well as in their direction, the patient's behavior influences the doctor's ability to fulfill his various role obligations. For example, a patient who worsens his condition because he does not follow important advice given by the doctor makes it more difficult for the doctor to reconcile his duties to act beneficently towards his patient, and to respect his autonomy; similarly, a patient who does not show up to scheduled appointments makes it more difficult for the doctor to distribute her resources - including her time - justly among her patients. ${ }^{30}$

30 At this point, the duty of the members of a health care system to keep healthcare costs as low as possible becomes evident: the doctor's duty of justice assumes a normatively relevant scarcity of resources, given that questions of justice arise only in conditions of moderate scarcity, and this in turn generates questions concerning the proper allocation of scarce resources 
Hence, the patient can make it easier or more difficult for the doctor to fulfill his moral obligations to the patient by cooperating or not cooperating. And this creates a role obligation of the patient to cooperate with the doctor - a moral role obligation, given that it is grounded in a justified interest of the doctor to fulfill her moral role obligations. This duty includes, but is not limited to, the duty to keep appointments and to be honest about one's condition; a duty to keep resources to a minimum; a duty to advance one's recovery; and a duty to follow the doctor's advice, as long as this can be reasonably demanded. ${ }^{31}$

Accordingly, patients have moral role obligations that apply to them as patients. These obligations are grounded in the fact that doctors have moral role obligations to their patients and a justified interest in fulfilling these obligations. Doctors' duties are duties directed to patients, and similarly, patients' duties are duties directed to doctors. However, there is an important difference between the duties of patients and doctors. The duties of doctors are freestanding in a certain sense: they exist independently of the duty of the patients. But the duties of patients are derivative of the duties of the doctors: the rationale for their duties is to not hinder the doctor in fulfilling their moral role obligations as doctors or to not create avoidable moral dilemmas for them. In a way, then, the role obligations of the patient stem not only from the social role of a patient, but also from the social role of a doctor - or more specifically, they stem from the moral role obligations of the doctor. Hence, the roles of doctor and patient not only depend on each other ontologically - they also do so normatively. And this explains the duties of patients. ${ }^{32}$

\footnotetext{
- and arguably a reciprocal duty on the part of members of a healthcare system not to waste any of the scarce resources that could be used to benefit other members. But even if such a background duty exists, it does not account fully for the normativity of the doctor-patient relationship.

31 It might not be possible to determine completely out of context when following the doctor's advice can be reasonably demanded, but certain cases seem to be clear: failing to take one's medicine simply because one does not feel like it certainly amounts to an objectionable form of failing to follow the doctor's advice; by contrast, certain religious beliefs might be weighty reasons that justify not doing so.

32 One might think that this argument leads to the consequence of doctors conveying their duties to patients. In times of an increasing juridification of the doctor-patient relationship, there is a danger of doctors letting their patients confirm the legitimacy of their actions, independent of the actual quality of the treatment. The worry might be that if fulfillment of the doctors' duties is what grounds patients' duties, doctors might merely be motivated to ensure confirmation of the fulfillment of their obligations, whatever they are. But this would be a misunderstanding of the view proposed here. Patients' duties are justified because by cooperating, they help doctors to fulfill their obligations. But the aim of patients' duties is not to help
} 
It must be emphasized that patients have a moral duty to cooperate with the doctor, not a duty of obedience. Patients' duties are duties not to hinder doctors in fulfilling their obligations. But this means that patients' duties only exist as long as doctors fulfill their role obligations. If a doctor fails to fulfill his obligations to the patient, the patient's cooperation is not mandatory for the fulfillment of the doctor's duties. After all, those obligations are not fulfilled, anyway. A duty of obedience would imply following the doctor's advice even in situations in which the patient has good reason to believe that the doctor does not fulfill his obligations. It would imply not questioning the doctor's decisions at all. A duty of cooperation is different: it leaves open (and can even require) the patient to be critical and possibly scrutinize whether the doctor fulfills his obligations. Patients ought to cooperate with the doctor, but not obey her.

\section{Concluding remarks}

Patients are not only bearers of moral rights, but also of moral duties. One important duty is the duty to cooperate with the doctor. This duty derives from the moral duties of the doctor: the rationale for this duty is the justified interest of the doctor in fulfilling her moral role obligations. By not cooperating, the patient can hinder the doctor from fulfilling her obligations and might even create avoidable moral dilemmas for her. Hence, he has a duty to cooperate.

To a certain degree, this duty is already recognized within treatment contracts. Such contracts usually involve a section concerning the client's responsibilities, and these responsibilities resemble the duty to cooperate as identified in this paper. In a way, then, the argument presented here is a moral justification for demanding the patient's compliance. And this might have important practical consequences: some moral duties are the proper object of juridical laws, and therefore also legal duties. If patients do in fact have a moral obligation to cooperate, there might also be grounds to establish legal procedures that enforce the patient's accountability for not cooperating with the doctor, and to establish legal duties to cooperate too.

doctors fulfill their obligations in the abstract. Rather, the aim is to help doctors act on those considerations that actually ground their obligations. Patients ought to cooperate because by doing so, they help doctors to act justly or beneficently, rather than to fulfill an obligation that happens to be to act justly or beneficently. I thank an anonymous referee for raising this objection. 
This, however, is only a tentative claim. It needs much more philosophical work to determine whether the moral duty of patients to cooperate should be turned into a legal obligation as well. There are good reasons to be skeptical here. After all, as mentioned, the patient's duty to cooperate does not hold absolutely, because, again, the duty to cooperate does not amount to a duty of obedience. One reason has already been mentioned: a duty of obedience would hold even if the doctor did not fulfill her role obligations. By contrast, the duty to cooperate does not hold in cases in which the doctor does not fulfill her obligations: given that it derives from the obligations of the doctor, it only holds on the condition that the doctor actually fulfills her obligations. The duty to cooperate can also cease if the doctor is unskilled or mistaken about the best course of action; as soon as the patient has good reason to believe that the doctor is either unskilled or mistaken, he no longer has a duty to cooperate. Given that patients' duties derive from doctors' duties, and that doctors' duties aim at protecting the specific vulnerability of patients, it follows that the patient has no duty to cooperate if the doctor fails to protect the patient's vulnerability. ${ }^{33}$

But there is another reason why the duty to cooperate does not turn into a duty of obedience: the autonomy of the patient. A duty of obedience would greatly conflict with the patient's autonomy, which is an important moral good - after all, the patient's autonomy is the reason why patients are bearers of moral obligations in the first place. Assigning patients moral duties emphasizes their moral status as autonomous beings, not just as helpless persons who rely on others. This can help to retrieve their dignity - in the eyes of others, but most importantly, in their own. ${ }^{34}$

33 At this point, one might ask for criteria to determine when a doctor fails to fulfill his obligations, or when he is unskilled or mistaken. This might be especially pressing in times when patients can google their symptoms and come to an often unjustified conclusion that the doctor is mistaken. I cannot offer a decisive general criterion for good reasons to believe that the doctor is mistaken here, and I am not sure that a general criterion can be given. But some general remarks are possible. First, if the doctor does not listen to the patient and fails to take him seriously, he fails to respect the patient's autonomy, thereby violating one of his duties. In such a case, the patient might have good reason to believe that the doctor did not take all relevant considerations into account when making his decision. Second, as Søren Holm has argued, especially in the case of chronic diseases, the patient, rather than the doctor, might be the expert on her disease and its specific manifestations (Holm 1993, 109). In such a case, a patient might come to a justified judgment that the prescriptions of the doctor merely follow some standard procedure that does not fit her specific case, and in such a case, her duty to cooperate might cease as well. I thank an anonymous referee for making me aware of the need to discuss this question. 
Acknowledgement: This work was supported by the Swiss National Science Foundation (SNSF) through the research project "The Normative Relevance of Agent-Relative Reasons" (Grant 100012_152918/1). I am grateful to Bert Heinrichs and two anonymous referees, as well as the audience of the Eighth International Conference on Ethics in Biology, Engineering \& Medicine at the SUNY Downstate Medical Center in Brooklyn, NY, for helpful comments on an earlier draft. 


\section{References}

Beauchamp, T. L., Childress, J. F. (2012): Principles of Biomedical Ethics. 12th ed. Oxford. Brighouse, H., Swift, A. (2014): Family Values. The Ethics of Parent-Child Relationships. Princeton.

Buetow, S. (2005): High need patients receiving targeted entitlements: what responsibilities do they have in primary health care? In: Journal of Medical Ethics 31, 304-306.

Darwall, S. (2013): Authority and Reasons: Exclusionary and Second-Personal, in: Darwall, S. (ed.): Morality, Authority, and Law. Essays in Second-Personal Ethics I. Oxford, 151-167.

Draper, H., Sorell, T. (2002): Patients' Responsibilities in Medical Ethics. In: Bioethics 16 (4), 335-352.

Dworkin, R. (1986): Law's Empire. Cambridge.

Evans, M. (2007): Do Patients Have Duties? In: Journal of Medical Ethics 33 (12), 689-694.

Foster, C. (2009): Choosing Life, Choosing Death: The Tyranny of Autonomy in Medical Ethics and Law. Oxford.

Hardimon, M. (1994): Role Obligations. In: The Journal of Philosophy 91 (7), 333-363.

Holm, S. (1993): What is Wrong with Compliance? In: Journal of Medical Ethics 19, 108-110.

Kangasniemi, M., Halkoaho, A., Länsimies-Antikainen, H., Pietilä, A. M. (2012): Duties of the patient: A tentative model based on metasynthesis. In: Nursing Ethics 19 (1), 58-67.

Kolodny, N. (2003): Love as Valuing a Relationship. In: Philosophical Review 112, 135-189.

Meyer, M. J. (1992): Patients' Duties. In: The Journal of Medicine and Philosophy 17, 541-555.

Mill, J. S. (1969): Utilitarianism. In: The Collected Works of John Stuart Mill. Ed. J. M. Robson.

Vol. X. London.

O’Neill, O. (2002): Autonomy and Trust in Bioethics. Cambridge.

Parsons, T. (1951): The Social System. Glencoe, IL.

- (1975): The Sick Role and the Role of the Physician Reconsidered. In: The Milbank Memorial Fund Quarterly. Health and Society 53 (3), 257-278.

Raz, J. (1989): Liberating Duties. In: Law and Philosophy 8, 3-21.

Ross, W. D. (1930): The Right and the Good. Oxford.

Scheffler, S. (2002): Boundaries and Allegiances. Oxford.

Schneider, C. (1998): The Practice of Autonomy: Patients, Duties, and Medical Decisions. Oxford.

Sciaraffa, S. (2011): Identification, Meaning, and the Normativity of Social Roles. In: European Journal of Philosophy 19 (1), 107-128.

Seglow, J. (2013): Defending Associative Duties. New York.

Wenar, L. (2013): The Nature of Claim-Rights. In: Ethics 123 (2), 202-229. 
Bereitgestellt von | UZH Hauptbibliothek / Zentralbibliothek Zürich 